\title{
Over de culturele uitwisseling tussen de Lage Landen en Polen aan de hand van de Nederlandse vertalingen van de Poolse hedendaagse literatuur
}

\author{
On the Cultural Exchange Between the Low Countries and Poland \\ in the Light of the Dutch Translations of Modern Polish Literature
}

Katarzyna Tryczyńska

\begin{abstract}
This paper attempts at analyzing the cultural exchange taking place due to literary translation. Culture is present in literary texts on almost every level. Numerous translating difficulties occur as a result of cultural differences between the source and target culture as well as the fact that the same reality is quite often expressed from a different perspective. The culturally anchored codes manifest themselves mostly in culture-specific items and that is why this article addresses the issue of such elements in the Dutch language translations of two Polish literary texts: "Mała apokalipsa" ["A minor apocalypse"] and "Początek" ["The beautiful Mrs. Seidenman"].
\end{abstract}

\section{Keywords}

culture-specific items, cultural transfer, literary translation, translation procedures 
In de huidige vertaalopvattingen wordt vertaling, en vooral de literaire vertaling, beschouwd als een brug tussen twee of meer culturen. De literaire vertaler volbrengt een zekere missie die door de geldende vertaalnormen alsook door de socio-culturele omstandigheden wordt bepaald. De literaire vertaling is een dynamische factor die de ontwikkeling van de cultuur, of zelfs de culturen in kwestie, teweegbrengt en een belangrijke rol speelt in het overwinnen van taalbarrières. De vertaalpraktijk en de manier waarop de literaire vertalingen in bepaalde literaire systemen circuleren, bevestigen ongetwijfeld de scheppende rol daarvan.

In wat volgt wordt een analyse gepresenteerd waarvoor het uitgangspunt wordt gevormd door cultuurspecifieke elementen bij de vertaling van twee gekozen Poolse hedendaagse romans in het Nederlands. Hier worden twee romans Mata apokalipsa [De kleine apocalyps] en Poczatek [De mooie mevrouw Seidenman] die deel uitmaken van het corpus van een breder onderzoek, onder de loep genomen ${ }^{1}$. De aandacht wordt besteed aan: de wijze waarop deze elementen in de Nederlandse vertalingen tot uitdrukking zijn gebracht, de vertaalstrategieën die door de vertalers zijn toegepast en de couleur locale van de originele teksten die al dan niet naar de doelteksten is overgebracht.

\section{Culturele specifiekheid en cultuurspecifieke elementen}

De meeste vertaalwetenschappers hebben nu een vergelijkbaar standpunt met betrekking tot de kwestie van de wederzijdse relatie tussen cultuur en vertalen, wat in de constatering van Bassnett (2007: 23) zichtbaar is: „translation is about language, but translation is also about the culture, for the two are inseparable". Het is dus duidelijk dat de vertaling niet los kan worden gezien van de cultuur waarin deze tot stand komt. De vertaling functioneert altijd in een continuüm, want „nothing has meaning "in isolation" (CARBONELL 1996: 86). Deze socioculturele context bepaalt bovendien de manier waarop deze tekst verder circuleert en door lezers wordt ontvangen. De nauwe relatie tussen vertalen en cultuur betekent ook dat vertalingen een bepaalde cultuur in een zekere mate beïnvloeden (DIXON 2004: 12) ${ }^{2}$. Toch kan de literaire vertaling niet uitsluitend als een product van de doeltaal en -cultuur worden gezien, maar als een ingewikkelde intellectuele handeling die verbonden is met de originele tekst, met de status daarvan in de broncultuur alsook de manier waarop deze tekst in vertaling in de broncultuur wordt ontvangen. Met andere woorden, we moeten altijd tenminste een tweedimensionale kijk hebben om alle subtiliteiten van het vertaalproces en de talrijke factoren, die het sturen, te kunnen inzien. De complexiteit van het vertaalproces maakt de taak van de vertaler niet zelden veeleisend en ingewikkeld. Bijzonder veel moeilijkheden treden op vooral bij vertalingen van lite-

1 Hier wordt het doctoraal onderzoek van de auteur bedoeld (TRYCZYŃSKA 2014).

2 De mate waarin vertalingen een bepaalde literatuur en cultuur beïnvloeden en tegelijk de positie van de vertaalde literatuur hangt af van de status die eraan wordt toegekend in de cultuur in kwestie (vgl. HEILBRON 2009: 110 e.v.; LAMBERT 2006: 131). 
raire teksten die diep in een bepaalde cultuur zijn ingebed en waarbij we dus met veel verwijzingen naar de cultuur, of culturen, in kwestie te maken hebben. Belangrijk is dat cultuur meestal op verschillende niveaus, om niet te zeggen op elk niveau van een literaire tekst waarneembaar is, het lijkt dus omnipresent te zijn. We kunnen ernaar zowel in de micro- als in de macrostructuur zoeken. Indien we de gelaagdheid van literaire werken in aanmerking nemen die als gevolg van een netwerk van interne verhoudingen tot stand komt, kunnen we evenals Naaijkens (2004: 19) constateren dat cultuur op een zekere manier in al die lagen te vinden valt. De elementen die deel van de microstructuur uitmaken, verbinden een bepaalde taal en cultuur met elkaar en worden als cultuurgebonden elementen ofwel culture-specific items (CSIs) aangeduid ${ }^{3}$. In een bepaalde context tonen ze op een specifieke manier een duidelijk verband met de cultuur van het land in kwestie en ze fungeren in de vertaalde literaire teksten als cultuurdragers. Om die redenen veroorzaken ze talrijke vertaalproblemen. $\mathrm{Al}$ die culturele verwijzingen ziet Evenepoel (2004: 126) als „sleutels die worden gesmeed door vertalers". Deze sleutels openen andere, onontdekte werelden voor lezers. Het belang van details is ontegenzeglijk, want dergelijke woorden kunnen ook zonder context niet zelden een cultuurdragend element zijn.

\section{Interculturele dialoog}

Het voorgaande in aanmerking nemend kunnen we ongetwijfeld vaststellen dat vertalen één van de manieren is waarop de interculturele dialoog tot stand komt. In deze dialoog vormt de vertaling een brug tussen twee of meer culturen.

„Een vertaling kan niet worden beschouwd als confrontatie van talen, maar van culturele systemen in de communicatie die door middel van deze teksten plaatsvindt. Deze confrontatie is echter niet op competitie en gevecht gericht, maar op ontmoeting, want dankzij deze confrontatie ontstaat de (inter)culturele dialoog." (SKIBIŃSKA 1999: 34, vertaling van mij - KT)

De culturele bagage is in de interculturele communicatie onontbeerlijk en beïnvloedt het wezen ervan in belangrijke mate. Om die redenen moet de vertaler, denkend aan de kennis waarover potentiële doeltekstlezers al dan niet beschikken, beslissen of hij/zij hen enige voorkennis wil verschaffen en op welke manier hij/zij die wil overbrengen. Hierbij speelt ook een ander aspect een belangrijke rol. De normen van de broncultuur zijn een essentiële factor bij de creatie van het origineel en bij vertalen geldt hetzelfde voor normen en gebruiken van de doelcultuur (BASSNETT \& LEFEVERE 1998: 93). De vertaler treedt op als bemiddelaar tussen deze twee systemen en moet door zijn/haar vertaalkeuzes een bevredigend resultaat waarborgen.

3 De definitie van culturele verwijzingen zoals die hier wordt gehanteerd alsook het karakter daarvan en de mogelijke vertaalmoeilijkheden die ze veroorzaken, zijn al eerder door de auteur gepresenteerd (vgl. TRYCZYŃSKA 2010: 162-166). 
Dit kan alleen als hij/zij zich bewust is van het belang van de culturele transfer die bij het vertalen plaatsvindt.

Vanuit dit oogpunt is het evident dat de overgang tussen culturen ertoe leidt dat de tekst en alle erin besloten informatie dienen te worden gefilterd om weer in de doeltekst goed tot uitdrukking te worden gegeven. In dit verband kan er zelfs van een dubbele filtering sprake zijn. In de eerste fase gebeurt deze vanuit het communicatief standpunt van de brontekstlezer denkende aan de belangrijke informatie van het origineel, de betekenis daarvan in de broncultuur en in de tweede wordt het standpunt ingenomen waaruit doeltekstlezers de tekst gaan bekijken. Het eindresultaat van het vertaalproces is als het ware een melange van beide perspectieven waar geen van hen wordt uitgesloten (PISARSKA, TOMASZKIEWICZ 1997: 157; SKIBIŃSKA 2004: 83). De vertaler dient dus in een nauwe interactie met de cultuur en de werkelijkheid van een bepaalde taal te werken, want hij/zij introduceert de vertaalde tekst in een nieuwe talige en culturele omgeving. Een volledige objectiviteit is echter een vergeefse poging, want de vertaler maakt telkens een subjectieve keuze uit ontelbare interpretatiemogelijkheden waaraan een literaire tekst kan worden onderworpen (ECO 2008: 129 e.v.). Om die redenen wordt de vertaler weleens als de tweede auteur van de tekst gezien die door zijn/haar interpretatie de tekst enigszins opnieuw creeert. Allerlei keuzes die hij/zij maakt, vormen bij elkaar een afspiegeling van zijn/ haar vertaalstrategie.

\section{Vertaaltechnieken en -strategieën}

Het blijkt dat de ingewikkelde relatie tussen vertalen en cultuur, of anders gezegd het wederzijdse inwerken, duidelijk in de vertaalkeuzes waarneembaar is. Volgens Venuti wordt elke stap in het gehele vertaalproces al vanaf de keuze van de teksten, de toepassing van vertaalstrategieën tot de uitgave en de receptie van de vertaalde teksten door verschillende geldende culturele waarden van de doelcultuur wordt bepaald (vgl. VENUTI 1995: 308).

Weloverwogen en verantwoorde beslissingen van de vertaler kunnen het vertaalproces op een juiste manier sturen en moeten altijd als een wegwijzer dienen. Zoals reeds opgemerkt, moet de bewuste vertaler de tekst aan een dubbele filtering onderwerpen. Indien hij/zij zich van zijn/haar functie als interculturele bemiddelaar bewust is, moet hij/zij zijn/haar vertaalwerk vanuit het macroniveau naar het microniveau uitvoeren. Dit betekent dat hij/zij eerst bepaalde keuzes moet maken met betrekking tot het macroniveau of anders gezegd tot zijn/haar algemene vertaalstrategie, en dan met betrekking tot het microniveau waarop hij/zij bepaalde vertaaltechnieken aanwendt. Deze beslissingen worden dus op twee niveaus van elke tekst gerealiseerd en niet zelden vloeien door elkaar heen. De vertaalstrategie wordt vaak als een algemene tactiek van de vertaler beschouwd en daarom denkt men erbij aan het macroniveau van de tekst. Het kan heel breed worden begrepen als een algemene aanpak ten opzichte van vertalen en anders nauwer bekeken is dit een manier waar- 
op een bepaald (vertaal)probleem wordt opgelost (vgl. DUKĀTE 2009: 76). De vertaalstrategie is superieur ten opzichte van vertaaltechnieken die op microstructureel niveau worden toegepast en vloeien voort uit de gekozen vertaalstrategie. Het brede spectrum vertaaltechnieken wordt weerspiegeld in de op het tekstuele niveau toegepaste vertaalkeuzes die in de hele tekst zichtbaar zijn (vgl. KWIECIŃSKI 2001: 120) ${ }^{4}$.

De kunst van vertalen wordt het meest tastbaar op de proef gesteld als de vertaler moeilijkheden tegenkomt die heel vaak door cultuurspecifieke verwijzingen worden veroorzaakt. De vertaalkeuzes van de vertaler zijn bijzonder belangrijk met het oog op de bemiddelende functie van de vertaling in de interculturele communicatie die we al reeds hebben genoemd. Indien we ons afvragen welke mogelijkheden de vertaler ter beschikking heeft om zo goed mogelijk voor een culturele transfer te zorgen, moeten we aan het brede spectrum van vertaaltechnieken denken. Om de vraag te kunnen beantwoorden welke vertaalstrategie en respectievelijk welke vertaaltechnieken het meest geschikt zijn, moeten we telkens een aantal factoren in acht nemen. Veel vertaaltheoretici hebben inmiddels vastgesteld dat geen vertaalstrategie objectief is en tevens niet als het meest geschikt kan worden bekeken, want deze dient altijd bepaalde doeleinden (DUKĀTE 2009: 121).

\section{Analyse}

Uit het voorgaande is gebleken dat de cultuur zich in de literaire vertaling grofweg op alle niveaus manifesteert. Nu trachten we na te gaan hoe dat eruitziet in het geval van de twee gekozen Nederlandse vertalingen: Mata apokalipsa [De kleine apocalyps] van Tadeusz Konwicki en Poczatek [De mooie mevrouw Seidenman] van Andrzej Szczypiorski. Beide romans zijn door dezelfde vertaler vertaald, namelijk door Gerard Rasch. Deze teksten maken deel uit het bovengenoemde doctoraal onderzoek van de auteur. Hier valt het op te merken dat het essentieel was voor de analyse die in het kader van dit onderzoek werd verricht, dat er teksten gekozen werden die op een bepaalde manier cultuurspecifiek waren.

In de vertaling van Mata apokalipsa werd een breed spectrum van vertaaltechnieken toegepast wat de onderstaande kolomgrafiek illustreert. We hebben wel met een opvallende aanwezigheid van twee vertaaltechnieken te maken en percentueel gezien komt het neer op een bijna hetzelfde aantal gevallen, telkens rond een vierde van alle geanalyseerde gevallen. Het gaat om een exotiserende vertaaltechniek - calque en normalisation - die tot de assimilerende vertaaltechnieken behoort. Het valt ook meteen op dat de assimilerende vertaaltechnieken het talrijkst zijn, want bij elkaar vormen ze bijna de helft van alle geanalyseerde cultuurspecifieke elementen (44\%). Toch zijn ook de exotiserende vertaaltechnieken goed gerepresenteerd (37\%). De derde groep

4 De termen vertaalstrategie en vertaaltechniek hangen onlosmakelijk samen met de concepten van foreignisation en domestication en respectievelijk exotisation and assimilation Een meer uitvoerige bespreking van dit probleem stelt de auteur in een andere publicatie voor (vgl. TRYCZYŃSKA 2010: 166-168). 
vertaaltechnieken, namelijk de tussenliggende vertaaltechnieken komen in $19 \%$ gevallen voor waarbij de vertaaltechnieken die een rijke uitleg bieden, dominant zijn. Op basis daarvan kunnen we vaststellen dat de vertaler ervoor heeft gezorgd om een zekere balans te behouden tussen alle vertaaltechnieken onderling en eerder naar een gulden middenweg zocht. Dit betekent dus dat de vertaler geen voorkeur had voor een totaal vervreemdende noch domesticerende vertaalstrategie.

Grafiek 1 Verspreiding van analyseresultaten per vertaaltechniek in "De kleine apocalyps"
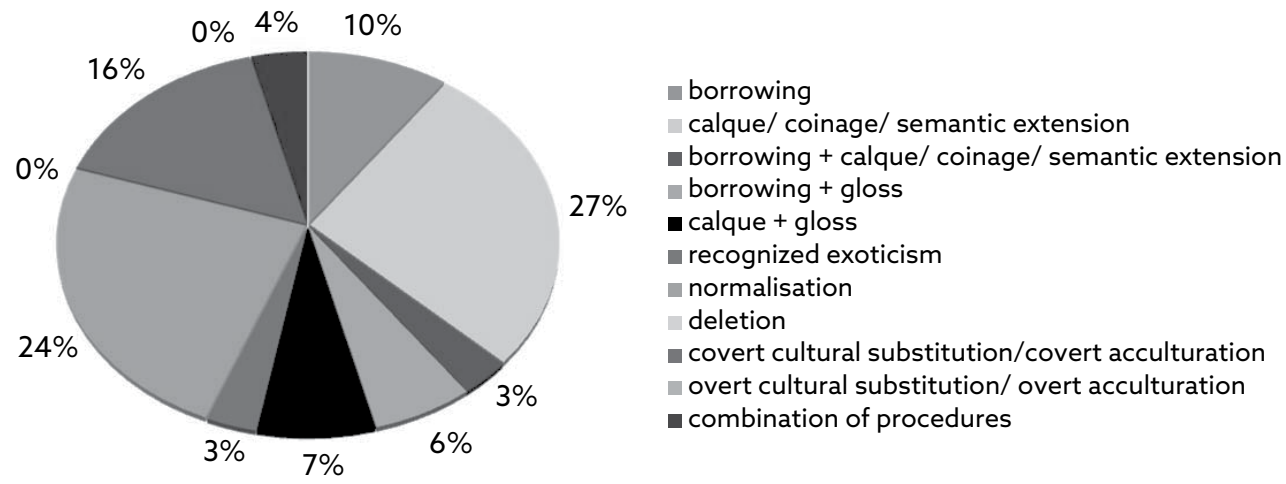

Grafiek 1 - analyse van CSIs in De kleine apocalyps

$\mathrm{Na}$ de bespreking van de toepassing van alle vertaaltechnieken trachten we te laten zien hoe dit er in concreto uitziet. Tot enkele voorbeelden van de toepassing van de meest dominante vertaaltechniek, dat wil zeggen calque, horen:

Pl. Biały nasz orzeł (p. 11) - N1. onze witte arend (p. 11),

Pl. drzewko szczęścia (p. 18) - Nl. geluksboompje (p. 17) of

Pl. sklep walutowy (p. 70) - Nl. dollarshop (p. 71).

De tweede vertaaltechniek wordt gerepresenteerd door zulke gevallen als:

Pl. mały fiat (p. 16) - N1. Fiatje (p. 16),

Pl. kierezyje (p. 32) - N1. Krakause mantels (p. 32),

Pl. elektroluks (p. 41) - N1. stofzuiger (p. 41) of

Pl. uliczny saturator (p. 44) - Nl. wagentje met de spuitwatermachine op de stoep (p. 45).

Er zijn ook nog twee vertaaltechnieken die een aanzienlijk deel uitmaken van alle gevallen en om die reden tonen we enkele voorbeelden van CSE's die door middel van: a) covert cultural substitution en b) borrowing zijn vertaald. Dit zijn:

a) Pl. wozy milicyjne (p. 12) - N1. politieauto's (p. 12),

Pl. podroby (p. 32) - Nl. varkensdarm (p. 32),

Pl. bar mleczny (p.33) - Nl. cafetaria (p.34)

b) Pl. krakowiak (p. 32) - Nl. krakowiak (p.32),

P1. Cepelia (p. 50) - N1. Cepelia (p. 51) of 
P1. Pan Tadeusz (p. 196) - Nl. Pan Tadeusz (p.202).

Het is opvallend dat er in de Nederlandse vertaling van Poczatek een geheel andere constellatie van vertaaltechnieken te vinden valt. Hier treedt één van de tussenliggende vertaaltechnieken op de voorgrond. Rasch heeft $36 \%$ cultuurgebonden elemtenten door middel van borrowing + gloss vertaald. De onderstaande grafiek laat duidelijk zien dat deze vertaaltechniek boven alle andere vertaaltechnieken uitmunt. Het valt op te merken dat de combinatie van borrowing en een gloss ook in De kleine apocalyps dominant is onder alle toegepaste tussenliggende vertaaltechnieken. De grafiek toont daarnaast ook dat er nog drie vertaaltechnieken frequent zijn en met bijna dezelfde intensiteit worden gebruikt. Het gaat om: borrowing, calque + gloss en normalisation, telkens een vertaaltechniek uit een andere categorie. Door het feit dat de tussenliggende vertaaltechnieken die een rijke uitleg over de vertaalde cultuurspecifieke elementen bieden, bij elkaar meer dan de helft van alle gevallen (54\%) vormen, kunnen we vaststellen dat Rasch een poging heeft ondernomen om in zijn vertaling 'het vreemde' te laten spreken en door extra commentaren aan te vullen en uit te leggen. Dit laat ons tot een conclusie komen dat er sprake kan zijn van een gematigde vertaalstrategie die tussen een extreem domesticerende en vervreemdende vertaalstrategie staat.

Grafiek 2 Verspreiding van analyseresultaten per vertaaltechniek in „De mooie mevrouw Seidenman"
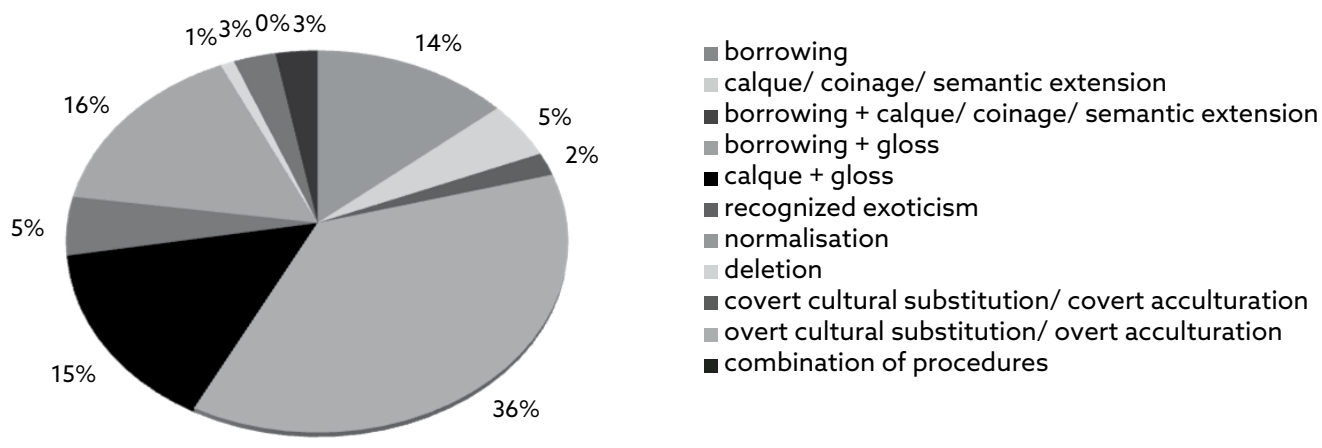

Grafiek 2 - analyse van CSIs in De mooie mevrouw Seidenman

Om dit beter toe te lichten willen we enkele voorbeelden van de onderzochte CSIs presenteren die in de vertaling De mooie mevrouw Seidenman aanwezig zijn. We beginnen met de vertaaltechniek waarvoor de vertaler de meeste voorkeur heeft - borrowing+gloss:

P1. Częstochowa (p. 55) - N1. Częstochowa5 (p. 48),

P1. Jasna Góra (p. 77) - N1. het klooster van Jasna Góra (p. 69),

5 Częstochowa: plaats waar het klooster van Jasna Góra (de Lichte Berg) staat met de beeltenis van de Zwarte Madonna, het Poolse Rome. 
P1. Pawiak (p. 93) - Nl. Pawiakgevangenis (p. 85).

Hier volgt een aantal voorbeelden van de drie vertaaltechnieken die alle drie rond $15 \%$ van alle gevallen bekleden normalisation:

P1. Bezpieka (p. 111) - Nl. Veiligheidsdienst (p. 101),

Pl. rogatywka (p. 153) - Nl. pet (p. 138),

calque+gloss:

Pl. szklane domy (p. 173) - Nl. glazen huizen ${ }^{6}$ (p. 158),

Pl. kampania wrześniowa (p. 152) - N1. septembercampagne van 1939 (p. 137)

en borrowing:

Pl. rapaport bielski (p. 119) - Nl. Bielitzer Rapaport (p. 108),

Pl. kacet (p. 208) - Nl. KZ (p. 191) of

Pl. Nowy Kurier Warszawski (p. 218) - Nl. Nowy Kurier Warszawski (p. 200).

\section{Samenvatting van de analyseresultaten}

De analyse toont aan dat we in beide vertalingen met dominante vertaaltechnieken te maken hebben. Dit neemt echter niet weg dat de andere vertaaltechnieken zich in een minieme minderheid bevinden, integendeel vormen ze een proportionele aanvulling op de dominante vertaaltechnieken. De procentuele verspreiding van de toepassing van afzonderlijke vertaaltechnieken is zichtbaar in beide boeken, maar ondanks dat kunnen we bepaalde regulariteiten bespeuren. In De kleine apocalyps komen twee vertaaltechnieken het vaakst voor en worden gekoppeld andere vertaaltechnieken die tamelijk proportioneel zijn verdeeld, het gaat namelijk om calque en normalisation. Wat normalisation betreft, komt het in De mooie mevrouw Seidenman overigens met een grote intensiteit voor waar we met een dominantie van een vervreemde vertaaltechniek te maken hebben, dat wil zeggen borrowing + gloss. Wat de tussenliggende vertaaltechnieken betreft, spannen ze de kroon in De mooie mevrouw Seidenman en in De kleine apocalyps vinden we slechts een klein aantal tussenliggende vertaaltechnieken die een rijke uitleg bieden. Ze kunnen als katalysatoren worden gezien die ervoor zorgen dat 'het vreemde' in een toegankelijke vorm aan de doeltekstlezers wordt aangeboden. In beide vertalingen komt deletion dat als een extreme vertaaloplossing wordt gezien, helemaal niet voor.

Omdat ik in mijn doctorale onderzoek niet alleen de toepassing van vertaaltechnieken, maar ook het effect van de toepassing daarvan op het macroniveau heb nagespeurd, wil ik er ook hier dieper op ingaan. De tot nu toe gepresenteerde voorbeelden worden hier zonder context aangehaald omdat het binnen het bestek van deze bijdrage niet mogelijk is om ze volledig te bespreken aan de hand van het toegepaste analysemodel dat ook de macrocontext in aanmerking neemt. Ze dienen hier om aan te tonen hoe breed het spectrum van cultuurspecifieke verwijzingen kan zijn alsook

6 glazen huizen: uit de roman 'Voorlente' (1924) van Stefan Żeromski (1864-1925), symbool van de hoop op betere tijden. 
hoe relatief hun karakter is. Het blijkt dus dat men niet van tevoren mag aannemen dat alleen bepaalde elementen van een literaire tekst cultuurspecifiek zijn, zulke elementen moeten altijd in relatie tot de doeltekst worden geïdentificeerd. Bovendien mogen de zogenaamde doorsnee gevallen niet buiten beschouwing worden gelaten, want juist deze elementen van een literaire tekst kunnen bijzonder ingewikkelde vertaalproblemen opleveren. Wat ik dus tracht te onderstrepen is dat een analyse die zich tot het microniveau van een literair werk beperkt, zonder meer onvoldoende is en het macroniveau moet er zonder enige twijfel altijd in aanmerking worden genomen.

Op basis van de uitgevoerde analyse kan worden geconstateerd dat bijna 86\% van alle vertaaltechnieken die zijn toegepast, een domesticerend karakter vertonen, waarvan aan normalisation graad 4 het meest vaak werd toegekend. Op een scala van 1 tot 4 is dit de hoogste mate van domestication. Belangrijk is dat er in $59 \%$ van alle onderzochte CSIs graad 3 werd toegekend. Dit betekent dat ruim de helft daarvan begrijpelijk is voor doeltekstlezers waarbij ze soms 'het vreemde' kunnen aanvoelen. Bovendien indiceert het ook dat de couleur locale op die manier in een zekere mate naar de doeltekst wordt overgebracht. De analyse toont aan dat ten eerste borrowing + gloss, dat wil zeggen een tussenliggende vertaaltechniek, die doorgaans een rijke uitleg biedt, de meest dominante vertaaltechniek met zo'n uitwerking is, ten tweede borrowing ook hoog scoort naast calque + gloss. Het feit dat borrowing een extreem exotiserende vertaaltechniek is en de cultuurspecifieke verwijzingen die door middel daarvan zijn vertaald, los van de context volledig onbegrijpelijk kunnen zijn voor doeltekstlezers, vormt een duidelijk bewijs dat het uiteindelijke effect van de breed begrepen context afhangt. We vinden er een bevestiging voor ook bij de beoordeling van het effect van CSIs die door middel van overige vertaaltechnieken zijn vertaald. De hoge waarden van de uiteindelijke beoordeling betekenen dat de mate van begrijpelijkheid van vreemde fenomenen die in de doeltekst voorkomen en het percentage ongetwijfeld hoog is wat cruciaal is voor de culturele transfer die op deze manier plaats kan vinden.

\section{Conclusies}

Het lijdt geen twijfel dat literaire vertalingen een verreikend effect hebben en bijna altijd tot de beeldvorming van de uitheemse literatuur en tegelijk van de cultuur in kwestie bijdragen (vgl. BOULOGNE 2013: 66 e.v.). De opmerking van Venuti kan als een bevestiging daarvan worden gezien: „translation wields enormous power in constructing representations of foreign cultures while it simultaneously constructs domestic subjects" (VENUTI 2002: 67). Dit citaat brengt alweer de kwestie van de onbetwistbare verwevenheid van vertalen en cultuur naar voren, want literair vertalen oefent een aanzienlijke invloed op de cultuur uit en tegelijk wordt het proces van literair vertalen door de cultuur bepaald. Daarnaast kan de impact van de vertaler zelf niet worden onderschat omdat de manier waarop vertalingen in de doelcultuur worden ontvangen in een grote mate afhangt van zijn/haar interpretatie van het 
origineel. In de vertaling valt immers „both the projection of the author and that of the translator" (NAAIJKENS 2008: 306) te bespeuren. Indien we ons afvragen in hoeverre doeltekstlezers bepaalde fenomenen uit de broncultuur die in de vertaling behouden zijn gebleven, juist kunnen ervaren en begrijpen, mogen we niet verwachten dat de associaties hetzelfde kunnen zijn. We moeten de mythe van de identieke ervaring van lezers verwerpen. Dit idee en een dergelijke verwachting lijken onacceptabel, omdat de manier waarop mensen de wereld waarnemen uitermate persoonlijk is en het gedeeltelijke karakter van de communicatie de kwintessens ervan is.

„Every reading of a text is a unique, unrepeatable act and a text is bound to evoke differing responses in different receivers." (HATIM \& MASON 1990: 4)

Dit geldt ook voor vertalingen die door elke lezer op zijn of haar eigen manier worden ervaren, telkens opnieuw gelezen en ondanks eventuele talige en culturele verschillen tenminste gedeeltelijk begrepen.

\section{Bibliografie}

BASSNETT, Susan (2007): ,Culture and Translation'. In: KUHIWCZAK, Piotr, Karin LITTAU (red.), A Companion to Translation Studies. Clevedon, Buffalo, Toronto, p. 13-76.

BASSNETT, Susan, LEFEVERE, André (1998): Constructing Cultures. Essays on Literary Translation. Clevedon, Philadelphia, Toronto, Sydney, Johannesburg.

BOULOGNE, Pieter (2013): ,Nietes-welles. Waarom vertaalwetenschap wel cruciaal is voor de Receptiewetenschap'. In: Filter 20 (1), p. 66-72.

CARBONELL, Ovidio (1996): The Exotic Space of Cultural Translation. In: ALVAREZ, Román [et.al.]: Translation, Power, Subversion. Clevedon - Philadelphia - Adelaide, p. 79-98.

DIXON, John S. (2004): ,Translation, culture and communication'. In: KITTEL, Harald [et.al.], Übersetzung Translation Traduction. Ein internationales Handbuch zur Übersetzungsforschung. An international Encyclopedia of Translation. Studies Encyclopédie internationale de la recherche sur la traduction. Berlin - New York, p.11-23.

DUKĀTE, Aiga (2009): Translation. Manipulation and Interpreting. Frankfurt am Main.

ECO, Umberto (2008): Dzieło otwarte: Forma i nieokreśloność w poetykach współczesnych, vertaald door L. Eustachiewicz [et al.]. Warszawa.

EVENEPOEL, Stefan (2004): ,Bij wijze van slot. Zoeken naar sleutels voor Notebooms Hotel‘. In: EVENEPOEL, Stefaan [et.al.]: Taal en cultuur in vertaling. De wereld van Cees Noteboom. Antwerpen - Apeldoorn, p. 123-127.

HATIM, Basil, MASON, Ian (1990): Discourse and the Translator. Harlow.

HEILBRON, Johan (2009 [1999]): 'Towards a sociology of translation. Book translations as a cultural world-system'. In: BAKER, Mona (red.): Translation studies. Critical Concepts in Linguistics, vol. II, p. 108-124.

KWIECIŃSKI, Piotr (2001): Disturbing strangeness, Foreignisation and domestication in translation procedures in the context of cultural assymetry. Torun.

LAMBERT, José (2006 [1988]): ,Twenty years of research on literary translation at the Katholieke Universiteit Leuven'. In: DELABASTITA, Dirk [et.al.], Functional Approaches to Culture and Translation Studies. Amsterdam, Philadelphia, p. 49-62.

NAAIJKENS, Ton (2008): ,Texts and the Dynamics of Cultural Transfer - Translations as Events'. 
In: Mutatis Mutandis: Revista Latinoamericana de Tradducción 1(2). Columbia: Universidad de Antioquia, p. 305-315.

NAAIJKENS, Ton (2004): ,Een wereld van verschil. Over taal en cultuur in vertaling'. In: EVENEPOEL, Stefaan [et.al.]: Taal en cultuur in vertaling. De wereld van Cees Noteboom. Antwerpen - Apeldoorn, p. 13-23.

PISARSKA, Alicja, TOMASZKIEWICZ, Teresa (1996): Współczesne koncepcje przekładoznawcze. Poznań.

SKIBIŃSKA, Elżbieta (2004): ,W szkole interkulturowości: problematyka różnic między kulturami w dydaktyce przekładu'. In: KROPIWIEC, Urszula [et.al.]: Między oryginałem a przekładem, 9: Czy istnieją szkoły przekładu w Polsce? Kraków, p. 79-90.

SKIBIŃSKA, Elżbieta (1999): Przekład a kultura. Elementy kulturowe we francuskich tłumaczeniach „Pana Tadeusza”. Wrocław: Wydawnictwo Uniwersytetu Wrocławskiego.

TRYCZYŃSKA, Katarzyna (2014): Vertaaltendensen in de Nederlandse vertalingen van Poolse hedendaagse romans. Een vergelijkende studie van cultuurgebonden elementen. Diss. Uniwersytet Wrocławski.

TRYCZYŃSKA, Katarzyna (2010): ,Over de transfer van Poolse cultuurgebonden elementen bij de vertaling. Enkele theoretische overwegingen'. In: PRĘDOTA, Stanisław (red.): Neerlandica Wratislaviensia XIX, p. 159-173.

VENUTI, Lawrence (2002 [1998]): The Scandals of Translation: Towards an Ethics of Difference. London.

Mgr. Katarzyna Tryczyńska, Ph.D. / katarzyna.tryczynska@uwr.edu.pl

Uniwersytet Wrocławski, Katedra Filologii Niderlandzkiej im. Erazma z Rotterdamu ul. Kuźnicza 21-22, 50-138 Wrocław, Poland 
